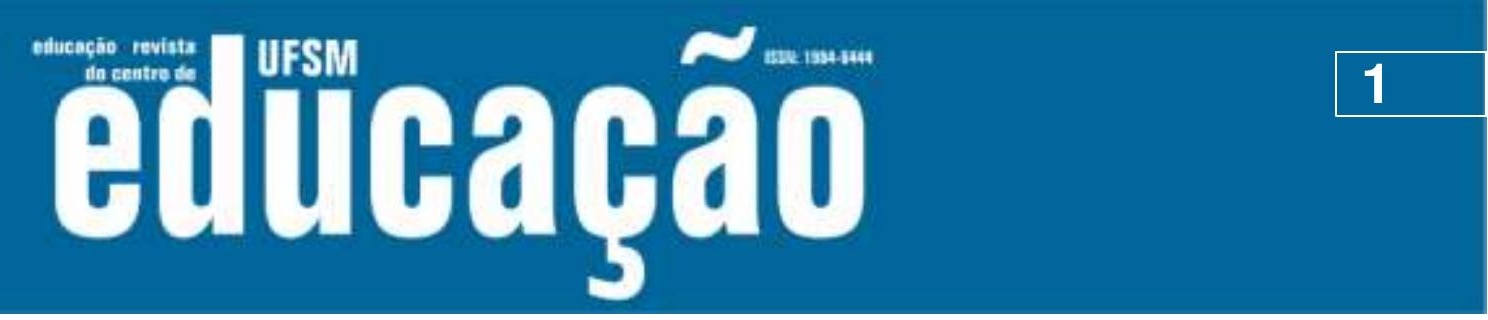

ISSN: 1984-6444 | http://dx.doi.org/10.5902/1984644430227

\title{
Gestão e controle social: em discussão o Conselho Municipal de Educação de Fortaleza/CE
}

Management and social control: in discussion the Municipal Council of Education of Fortaleza/CE

\section{Clarice Zientarski}

Professora doutora da Universidade Federal do Ceará, Fortaleza, Ceará, Brasil.

Hermeson Claudio Mendonça Menezes

Mestrando em Educação pela Universidade Federal do Ceará, Fortaleza, Ceará, Brasil.

Sônia de Oliveira da Silva

Mestranda em Educação pela Universidade Federal do Ceará, Fortaleza, Ceará, Brasil.

Endereço: Universidade Federal do Ceará, Faculdade de Educação. Rua Waldery Uchôa - até 727/728. Benfica. CEP: 60020110. Fortaleza, Ceará, Brasil.

E-mail: claricezientarski@yahoo.com.br _ azraellevi@gmail.com sonialiver@gmail.com

Recebido em 04 de dezembro de 2017

Aprovado em 28 de novembro de 2018

\section{RESUMO}

Esse trabalho analisa a ação e atuação do Conselho Municipal de Educação de Fortaleza, no Estado do Ceará no período (2014-2016), com o intuito de problematizar e identificar se este se apresenta como um espaço público de gestão e controle social, bem como um mecanismo de participação popular, buscando ainda compreender as possibilidades da Gestão Democrática em um contexto da sociedade capitalista atual (em plena reestruturação produtiva), crivada por políticas que agudizam a crise social brasileira, como as reformas e contrarreformas que reforçam a exclusão de grande parte da população brasileira do processo educacional. Metodologicamente trata-se de uma pesquisa com abordagem qualitativa-quantitativa, cujos instrumentos de análise são as Atas das reuniões do Conselho Municipal de Educação de Fortaleza ocorridas no triênio 2014-2016. Conclui a partir dos documentos e dos dados obtidos por meio da UNCME, que apesar de ainda ser um instrumento imperfeito - 


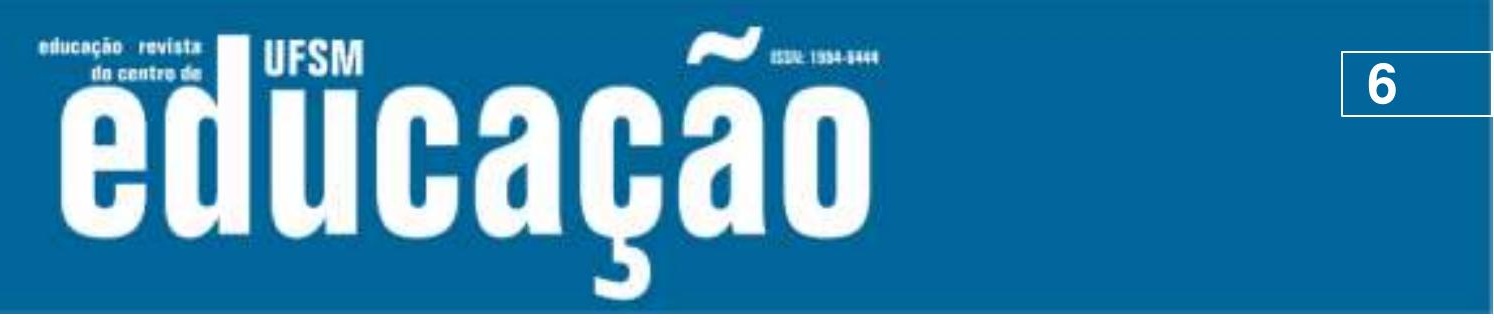

ISSN: 1984-6444 | http://dx.doi.org/10.5902/1984644430227

Baquero (2008) apresenta uma compreensão elucidativa dessa questão e ao mesmo, tempo traz um problema inquietante ao sublinhar que atribuir um "peso exclusivo a regras, instituições e procedimentos, em detrimento da compreensão do papel que a história, a cultura política e o próprio ser humano exercem na configuração das representações políticas", pode "subestimar os obstáculos existentes para alcançar uma democracia plena". (BAQUERO, 2008, p. 381).

Até que ponto os Conselhos em uma lógica de "naturalização" do status quo, tornam-se reprodutores sistêmicos do capitalismo, ao afirmar-se, seguindo uma concepção defendida por Baquero, que se deve ter uma "cidadania ativa" "sem que isso comprometa as instituições convencionais de mediação política"? Como interpretar, os avanços relativos à instalação e funcionamento dos CME sem cair no mero abstracionismo do marco legal? Diante disso, conceitos como Gestão Democrática, representatividade, cidadania e liberdade são reinterpretados.

Esses problemas estão intrínsecos, por sua vez, na análise sobre a criação, função e operacionalidade dos CME. Evidencia-se a indissociabilidade da análise referente à democracia e ao capitalismo, para a correta compreensão da Gestão Democrática e da operacionalidade dos CME, uma vez que a Democracia no sistema capitalista. Como salienta Coutinho (1979) é difusa, contraditória, marcada por uma bipolaridade, ora aparente, ora formal. Nesse movimento dúbio não basta ao cidadão 'fazer parte', mas 'tomar parte' efetivamente das esferas diretivas do poder, rompendo com o que Bordenave (1994, p. 22) denomina "participação provocada, dirigida ou manipulada [...] por agentes externos, que ajudam outros a realizarem seus objetivos" Romper essa lógica, objetivando a emancipação humana, só é possível em um espaço democrático que possibilite "fazer parte, tomar parte, ter parte, ser parte".

Neste contexto, convém salientar que a criação do Conselho Municipal de Educação respalda-se legalmente na Constituição Federal de 1998, na LDB № 9.394/96, no Plano Nacional de Educação, Lei no 10.172 de 09/01/01, novamente presente no PNE 2014/2024 - Lei no 13.005/2014, bem como nos princípios da Gestão Democrática e participativa do ensino público, com funções normativa, consultiva, deliberativa e fiscalizadora. 


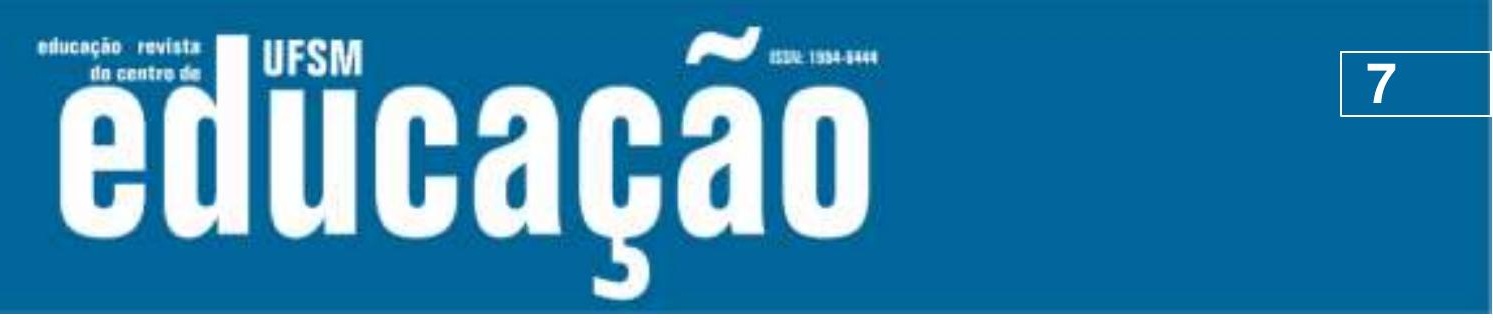

ISSN: 1984-6444 | http://dx.doi.org/10.5902/1984644430227

As ideias de participação e controle social presentes nos próprios documentos de criação dos conselhos destacam que elas: "[...] estão intimamente relacionadas: por meio da participação na gestão pública, os cidadãos podem intervir na tomada da decisão administrativa", orientam a "Administração para que adote medidas que realmente atendam ao interesse público" e, ainda, "ao mesmo tempo, podem exercer controle sobre a ação do Estado, exigindo que o gestor público preste contas de sua atuação". (BRASIL, C.S. 2017, s/p).

Alicerçado nessas argumentações, portanto, analisa-se a atuação e a função do CMEF como mecanismo de participação, com enfoque especial na ação dos conselheiros, compreendendo este CME como campo fértil para a luta de classes, espaço de tensionamento para a reflexão do significado de uma Gestão Democrática da Educação e indicador de caminhos para a sua efetivação.

\section{Gestão Democrática: relações humanas sob a égide capitalista}

Hobsbawm (1917-2012) apresenta o século XX como o "amplexo dos extremos". Um século paradoxal marcado tanto pelas catástrofes e barbáries sociais como pela inventividade humana. Manifestada no progresso científico e tecnológico, pela sede libertária, bem como pela fúria autoritária. No mundo do pós-guerra, viu-se o fervilhar dos debates em torno da democracia, sobremodo com o advento do Welfare State (Estado do Bem Estar Social) sendo que, ao final do século assistiu-se a crise desse modelo político-social e do socialismo real em movimento oposto, o sistema capitalista avançou de forma voraz, travestido em democracia de mercado, a qual, no amplexo dos extremos, estabeleceu outra maneira relacional entre Estado e sociedade: o Estado Neoliberal e a sociedade de mercado, trazendo à cena a discussão em torno das concepções de representatividade e participação política da sociedade.

Coutinho (2002) afirma que:

O processo de crescente democratização, de socialização da política, chocase com a apropriação privada dos mecanismos de poder. Temos aqui uma contradição: o fato de que haja um número cada vez maior de pessoas participando politicamente, participando organizadamente, constituindo-se como sujeitos coletivos, choca-se com a permanência de um Estado apropriado restritamente por um pequeno grupo de pessoas, por membros 


\section{U Usm Eutuarã}

ISSN: 1984-6444 | http://dx.doi.org/10.5902/1984644430227

da classe economicamente dominante ou por uma restrita burocracia a seu serviço. (COUTINHO, 2002, p.17).

Foi nesse contexto, de debates em torno da Democracia vista por Rosenfield (1994) como uma personificação da própria concepção de Estado, pois (legitima o poder deste), que no apagar do século XX e alvorecer do XXI, passou-se a definir diretrizes políticas objetivando uma nova forma de gestão pública, ancorada nos preceitos da administração de organizações privadas, propondo uma (contra)reforma do Estado (BEHRING, 2008). Implementou-se a minimização da participação do Estado na esfera dos serviços públicos, consequência da racionalidade administrativa e das políticas neoliberais, com repercussão direta na gestão escolar e na própria prática educativa.

Em uma sociedade de mercado imbricada no neoliberalismo e na globalização, torna-se imperiosa a inserção de novos sujeitos, seja como exército de reserva de mão de obra, seja como consumidores. As mudanças nas políticas educacionais efetivadas em sincronia orquestral com a agenda internacional (Conferência Mundial de Educação para Todos - EPT - Jomtien, 1990; Consenso de Washington - 1995; Conferência Mundial de Educação para Todos - EPT - Dakar, 2000) ditada pelos organismos internacionais, exigiram a implementação de reformas que atendessem às necessidades oriundas da reestruturação produtiva do Capital. (SHIROMA; MORAES; EVANGELISTA, 2002).

Nesse contexto, as políticas educacionais dos Estados neoliberais têm como finalidade cumprir o papel de reprodutor sistêmico do Capital, da formação social do capitalismo a partir da alienação do sujeito histórico, transformado em mero ator social: cidadão proativo, partícipe como mero eleitor na política partidária eleitoral e atuante na sociedade do voluntariado (por exemplo, a ação voluntária dos Amigos da Escola).

Essa é a concepção de democracia, de acordo com os ditames burgueses, coadunada com os princípios do liberalismo, "[...] a organização escolar é tomada como uma realidade objetiva, neutra, técnica que funciona racionalmente; [...], de modo a alcançar maiores índices de eficácia e eficiência" (LIBÂNEO, 2001, p. 96).

Sobre as concepções que mobilizaram esta onda reformista na área educacional, ao 


\section{U Us: oittrabat

ISSN: 1984-6444 | http://dx.doi.org/10.5902/1984644430227

final do século XX, Krawczyk (2008, p. 47) afirma que neste ideário reformista "buscava-se conciliar as diretrizes internacionais para a constituição de uma nova forma de gestão da educação e da escola". Diante do "exíguo atendimento à demanda do ensino fundamental e médio e dos altos índices de fracasso e evasão escolar".

\section{Por sua vez:}

Essas situações evidenciam que a proposta de democratização das instituições educacionais se apoia no projeto neoliberal, cuja política de descentralização de poder institui, como consequência, a possibilidade da participação da comunidade nas instituições, o que justifica as grandes dificuldades para a concretização de uma democracia direta. (ZIENTARSKI; SAGRILLO; PEREIRA, 2013, p.125).

Nesse prisma, conforme Bianchetti (1999, p.27), a proposta neoliberal converte-se no "fundamento de uma nova ordem internacional, reformulada a partir das novas condições do desenvolvimento da ciência e da tecnologia", leva, portanto, a uma concepção dominante na sociedade e, naturalmente, no cotidiano que envolve o meio educacional.

O Estado brasileiro, alinhado às políticas macroeconômicas neoliberais passou por um processo de reorganização atendendo as demandas das agências multilaterais, ainda na década de 1980, que estabeleceram através de acordos internacionais a prioridade à Educação Básica, conforme a Constituição de 1988, em seu art. 205 que estabelece a "educação como direito de todos e dever do Estado e da família", sendo "promovida e incentivada com a colaboração da sociedade, visando ao pleno desenvolvimento da pessoa, seu preparo para o exercício da cidadania e sua qualificação para o trabalho".

Em sintonia com a conjuntura mundial delineia-se no Brasil uma ampla "reforma do Estado", à qual será apregoada na década de 1990, no documento Plano Diretor da Reforma do Aparelho do Estado (1995), organizado pelo Ministério da Administração Federal e Reforma do Estado (MARE), estando à frente da pasta o Sr. Bresser Pereira (1995-1998).

Em relação à educação, desenvolveu-se uma nova cultura institucional, de matriz organizacional, objetivando enxugar custos operacionais dos espaços escolares, alinhando-as a novas formas de gestão (RAMOS, 2009). Implementam-se nesse viés, políticas e ações como o Plano Decenal de Educação PDE, a 


\section{U usm

ISSN: 1984-6444 | http://dx.doi.org/10.5902/1984644430227

consonância com os princípios da Conferência de Jomtien (1990) e com o Relatório Delors (1996).

Dentre as políticas educacionais adotadas no Ceará, e que refletem tais ideias neoliberais, destacam-se: "Todos pela Educação de Qualidade para Todos"/ "Plano de Desenvolvimento Sustentável" (Tasso Jereissati, 1995-1998), "Educação Básica de Qualidade no Ceará /Escola do Novo Milênio" (Tasso Jereissati, 1999-2002) e "Plano de Educação Básica/ Escola Melhor, Vida Melhor" (Lúcio Alcântara, 20032006), "Um Grande Salto, o Ceará Merece/ Programa Alfabetização na Idade Certa" (Cid Gomes, 2007-2010).

Os referidos programas ou projetos educacionais, supracitados, dos governos cearenses refletem, em seu arcabouço teórico, os princípios de construção de um projeto hegemônico de nação, no qual a educação ocupa centralidade. Seja na ampliação da inserção do setor privado na esfera da educação pública, seja no âmbito da formulação de políticas e da mobilização social, que busca contribuir para a ocultação dos conflitos de classe, tornando mais complexa a compreensão da realidade.

Diante do exposto pode-se perceber a existência de ideários antagônicos: de um lado o governamental, com seus projetos neoliberais, que privam a sociedade de participarem efetivamente dos processos decisórios, bem como, de ter acesso a uma educação emancipadora; e, de outro lado, a partir de uma concepção gramsciana, tem-se a convicção que se pode travar uma luta contra-hegemônica nos espaços, ou frestas do próprio sistema, no qual o CME se coloca como uma campo de possibilidades para este tensionamento, para esta "guerra de posição".

Ao compreender-se a existência de projetos políticos antagônicos, percebe-se que há uma distinção na concepção de Gestão Democrática: uma na perspectiva gramsciana, dos trabalhadores, da classe dos subalternos; e outra concepção de Gestão Burguesa. Esta distinção, que está no palco da luta de classes deve instigar a sociedade civil a ocupar seu papel sócio histórico, e aos intelectuais orgânicos da classe trabalhadora a gerarem um movimento contra hegemônico. Nessa perspectiva, aludem os $\mathrm{CME}$, instalados em meio às questões dialéticas que permeiam grupos escolhidos para representar setores da sociedade. 


\title{
Lusm

ISSN: 1984-6444 | http://dx.doi.org/10.5902/1984644430227

\section{Conselhos Municipais de Educação}

A Constituição de 1988 (Artigo 206) e a LDB no 9.364/96 (Artigo 14) baseada em princípios de democracia e de descentralização administrativa e política, propiciaram, a partir da década de 1990 no Brasil o avanço/criação de mecanismos de participação popular na esfera educacional, canais de participação da sociedade civil nas esferas decisórias cujos espaços. Outrora, eram exclusivos do poder hegemônico - Estado burguês, centralizador e elitista. Embora tais mecanismos sejam fruto de aspirações de ideólogos e idealistas de uma educação libertária/emancipadora, paradoxalmente, eles se inserem na lógica das reformas educacionais apregoadas por organismos e agências multilaterais.

Dentre estes mecanismos os conselhos populares e participação popular se apresentam como instâncias de participação da sociedade nos espaços públicos. Ao abordar a temática "Conselhos Populares e Participação Popular", Gohn (2006) discorre sobre as formas históricas dos conselhos:

\begin{abstract}
A Forma "conselho", utilizada na gestão pública ou em coletivos organizados da sociedade civil, não é nova na História. Alguns pesquisadores afirmam que os conselhos são uma invenção tão antiga como a própria democracia participativa e datam suas origens nos clãs visigodos. Em Portugal, entre os séculos XII e XV, foram criados "conselhos" municipais (escrita da época, com c), como forma político-administrativa de Portugal, em relação às suas colônias. (GOHN, 2006, p. 5).
\end{abstract}

Encontram-se ainda modelos de Conselhos na Comuna de Paris. Sovietes russos na Alemanha nos anos 1920 e nos modelos estudados por Gramsci, com os Conselhos de Fábrica, no qual todos os sujeitos que constituem a escola são importantes em suas funções seja enquanto: professor, diretor, funcionário da limpeza, estudante ou membro da comunidade.

Na perspectiva gramsciana constitui-se um único órgão forte (partido forte), coeso, uma escola para as "classes subalternas"/trabalhadores se educarem conscientemente, visando a sua implementação na Gestão Democrática Operária. (GRAMSCI, 2004, p.246-447).

Já no Brasil, segundo Bordignon (2009), os Conselhos, enquanto ideia, estão presentes desde o período do Império Brasileiro mas somente foram 


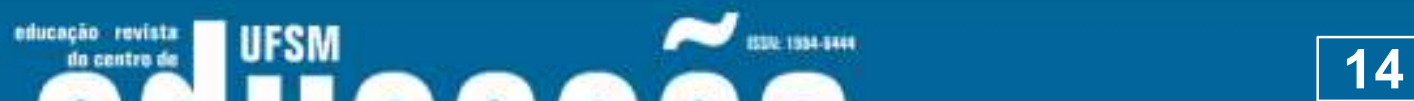

ISSN: 1984-6444 | http://dx.doi.org/10.5902/1984644430227

institucionalizados pelas Bases da Educação Nacional, a 1ª LDB - Lei oํ 4.024/1961 sendo que, historicamente os Conselhos foram definidos como órgãos técnicos de assessoramento, onde o Estado e a sociedade civil não dialogavam.

Na Constituição Federal de 1988, em seu Art. № 206 são estabelecidos os princípios pelos quais devem ser ministrados o ensino, sendo a Gestão Democrática do ensino público um desses princípios, os quais, de acordo com a LDB № 9.494/96 em seu Art no 14, deve-se observar as suas peculiaridades: "I - participação dos profissionais da educação na elaboração do projeto pedagógico da escola; II participação das comunidades escolar e local em conselhos escolares ou equivalentes".

Nesta lógica, como instrumentos para o exercício de uma Gestão Democrática da Educação, os Conselhos são pensados e nascem como fruto de uma tensão e correlação de forças: por um lado permitem que a sociedade civil participe ativamente da formulação, implementação e controle das políticas educacionais no espaço da escola, por outro lado, estão inseridos na lógica da (contra)reforma do Estado, o qual busca eximir-se de suas responsabilidades sociais atendendo aos ditames neoliberais, tratando a atuação da sociedade no sistema democrático apenas na perspectiva representativa e não participativa.

Ao discutir sobre a função e atuação do $\mathrm{CMEF}$, a análise fundamenta-se nas Atas das reuniões do triênio 2014-2016. Busca-se identificar o espaço no qual se insere o Conselho, as suas práticas, suas limitações, sua ação, sua atuação e os conflitos inerentes ao seu funcionamento, para concluir se de fato trata-se de um mecanismo democrático. Assim, entre os dados obtidos no levantamento, sendo analisadas as 25 Atas das reuniões que ocorreram entre 2014-2016, um dos mais preocupantes refere-se à frequência ou composição dos quadros que se fizeram presentes nas Reuniões Ordinárias e Extraordinárias do CMEF.

De um total de 25 (vinte e cinco) atas analisadas em apenas 02 (duas) reuniões estiveram presentes os representantes estudantis em apenas 01 (uma) estavam presentes representantes dos pais de estudantes. Em todas as reuniões a presença majoritária se fez por meio dos representantes de professores do Ensino Fundamental, da Educação Infantil e Conselho Municipal de Diretores. 


\section{U usm

ISSN: 1984-6444 | http://dx.doi.org/10.5902/1984644430227

perde em legitimidade, mantendo simplesmente sua dimensão formal. (BAQUERO, 2008, p. 381) (grifo nosso).

Esta é a noção de democracia e da atuação do CMEF, expressas neste documento. Com atitudes como estas tomadas pela SME nega-se a participação popular, a descentralização das decisões e limita-se a ação e atuação do Conselho. Cabe salientar, entretanto, que dentre os conselheiros, alguns compreendem seu papel e sua importância, como, por exemplo, na afirmação da Conselheira (representante dos professores da educação infantil) Gardênia Baima, que argumentou que não concordava com:

[...] o pedido de desculpas por parte do Secretário; que, em sua opinião, tratase de uma questão de planejamento e, como resolver, de forma provisória, uma situação que já é recorrente? Pois não está havendo cumprimento da Resolução pela SME no que se refere às Diretrizes de Matrícula; em sua opinião, deveria haver uma ampla discussão sobre o assunto. (CME/Fa, ATA LXXX, Data, 10/12/2014).

Depreende-se do fragmento acima que embora não se exercite plenamente a democracia nem este espaço de deliberação, ainda assim ele representa um campo profícuo de disputas por hegemonia. Observa-se esta situação quando na sequência da Ata encontra-se registrada a fala do Secretário respondendo à Conselheira Gardênia que: "sua intenção, ao pedir desculpas ao CME, não foi para fugir da responsabilidade, mas para tentar minimizar um ato equivocado da Secretaria, tendo em vista a autoridade e o grande respeito que tem pelas normas emanadas deste Conselho". (CME/Fa, Ata LXXX de 10/12/2014).

A Conselheira Gardênia representando também o Sindicato dos professores, na Ata LXXIV faz uma afirmação na qual delineia-se um aspecto da asseveração de Gramsci: "a quem recorrer se o Conselho tem uma Resolução e não está sendo cumprida?" (CME/Fa, ATA LXXIV DATA 07/05/2014). Neste caso, a Conselheira referia-se a Ação e Atuação do CME que Conforme a Lei n 9.317 de 14 de dezembro de 2007, que o instituiu tem autonomia:

\footnotetext{
O Conselho Municipal de Educação de Fortaleza (CME), órgão normativo e representativo, de natureza técnico pedagógica e de participação social, terá autonomia administrativa, sendo vinculado ao órgão executivo central. Parágrafo Único - O Conselho Municipal de Educação de Fortaleza (CME) cumprirá as funções normativa, consultiva, deliberativa, avaliativa e fiscalizadora. (FORTALEZA, DO. № 13.719. 2007, p. 01).
} 


\section{Lusm

ISSN: 1984-6444 | http://dx.doi.org/10.5902/1984644430227

Deliberar, portanto, implica na possibilidade de participar das decisões e não somente referendar o que já foi decidido pelo Executivo Municipal. Em relação à ação do CME constatou-se que as pautas giram em torno de assuntos que dizem respeito a: credenciamento das escolas, abertura de vagas, inclusão de alunos com deficiência, denúncias, estrutura das escolas, participação em eventos, atribuições dos membros das comissões, discussão sobre proposta de alteração da Lei de Criação do $\mathrm{CME}$ dentre outros que são identificados em várias atas.

O exercício consciente do controle social por parte dos cidadãos constituidores dos CME está vinculado ao modelo de gestão da política da própria sociedade. Para Oliveira "o controle social é exercido sobre e na esfera pública entende-se então, que todos os cidadãos são a princípio detentores do poder de controlar. Isso supõe apropriação tanto pelo conhecimento quanto pela participação das decisões e ações públicas". (OLIVEIRA, 1999, p.9).

Portanto, uma vez constituídos os $\mathrm{CME}$ isso não garante sua atuação de forma a atender os quesitos para o pleno exercício de uma Gestão Democrática. Ainda sobre isso Gohn (2000) afirma:

Para que tenham eficácia e efetividade na área em que atuam, e na
sociedade de uma forma geral, é necessário desenvolver algumas condições
e articulações; é preciso dar peso político a essa representação e
consequência a luta dos segmentos sociais que acreditaram e lutaram pela
democratização dos espaços públicos. (GOHN, 2000, p. 181).

Assumir uma nova prática de gestão que adote concepções democráticas em uma perspectiva gramsciana sedimentadora de uma educação emancipadora, rompendo com paradigmas alienantes de nossa sociedade capitalista e neoliberal, culturalmente estabelecidos, é desafiador. A apropriação de projetos da "classe dos subalternos" por parte dos grupos hegemônicos tende a gerar espaços políticos esvaziados de poder decisórios, tornando-os meramente consultivos ou estatísticos o que exige contra essa tendência, uma contínua ação de enfrentamento por parte da sociedade civil a qual deve impedir que falsos democratas se apropriem dos cargos administrativos e/ou representativos ação típica de "lideranças" patrimonialista que subvertem o público no privado.

Pode-se asseverar que esse processo de participação não acontece de forma espontânea, ao contrário, ele se dá em um processo histórico construído 


\section{Lism eltuarao}

ISSN: 1984-6444 | http://dx.doi.org/10.5902/1984644430227

Nesta esteira, o espaço do conselho, embora sem caráter deliberativo real (salientando-se que na esfera municipal, eles devem ter caráter deliberativo), representa de certa maneira, um ambiente profícuo de disputa política, almejado por candidatáveis, pelo poder público, por vereadores, burocratas, dentre outros.

Essa asseveração reitera que a educação é um espaço de conflitos. Além disso, por um lado existem recursos vultuosos destinados às escolas públicas que despertam o interesse desses segmentos, inclusive das instituições privadas de ensino e organizações não governamentais, que não querem abrir mão deste mecanismo de participação. E por outro lado, a participação e o "poder" de estar em uma instância na qual as políticas públicas são discutidas e socializadas, antes da sociedade civil tomar conhecimento, gera nestes "políticos" certo poder de barganha do qual não se pode prescindir.

Nesse sentido, embora não seja o foco desse artigo analisar dados do Estado do Ceará em seu conjunto, existe um desdobramento dessa mesma política, não apenas no município de Fortaleza, mas nos mais variados municípios do Ceará, tendo em vista que, em relação à criação dos $\mathrm{CME}$ e o credenciamento das escolas pelos Conselhos, os índices obtidos junto ao Banco de dados da UNCME apresentam uma realidade inconteste.

Os dados coletados mostraram que apesar dos Conselhos constituírem uma prerrogativa legal e estarem presentes em $82 \%$ (oitenta e dois por cento) dos 184 (cento e oitenta e quatro) municípios cearenses, a participação e a atuação desses Conselhos, em sua grande maioria, tem um caráter meramente consultivo.

Em relação ao credenciamento da escola por parte dos conselhos, os dados mostraram que em apenas 14\% dos CME o princípio apontado na LDB, no 9.394, Art. no 11 - IV - "autorizar, credenciar e supervisionar os estabelecimentos do seu sistema de ensino" é de fato materializado. Tais dados reafirmam as análises relativas à fragilidade na qual permeiam a criação e a efetiva atuação dos CME, que opõem a dimensão formal legal e a atuação, de fato dessas instâncias político-sociais.

Diante desse amálgama jurídico, social e político, ao se analisar empiricamente a realidade dos CME no Estado do Ceará tem-se um cenário desalentador, que conduz ao entendimento dos motivos que geram a predominância: da falta de 


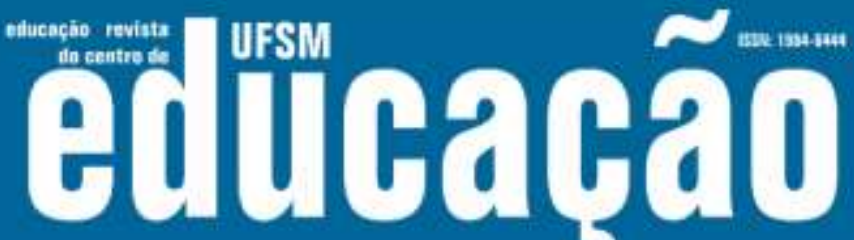

ISSN: 1984-6444 | http://dx.doi.org/10.5902/1984644430227

recursos, infraestruturas precárias, predomínio do caráter meramente consultivo dos conselhos, participação residual dos conselheiros nas reuniões, baixo grau de institucionalização, limitada autonomia, forte dependência em relação ao poder executivo Estadual/Municipal, forte influência do poder local, muitas vezes atuando com intensa ingerência, uso político eleitoral dos conselhos, instrumentalização dos conselhos com o fim de alocação/liberação de verbas dos órgãos governamentais, dentre outros aspectos. De uma maneira geral, compreende-se que apesar de todas as dificuldades e desafios na gestão democrática da educação e atuação dos conselhos, eles são uma potencialidade a ser cultivada e apropriada pela comunidade (Paro, 2008).

\section{Considerações finais}

Ao tratar sobre Gestão Democrática conforme salientado anteriormente é necessário que se estabeleça a relação entre democracia, sociedade e Estado no modo de produção capitalista, tendo em vista que no capitalismo a democracia mostra-se frágil, tênue e difusa. Nesse prisma, embora com estas características, a gestão democrática representa ainda uma possibilidade de participação pois, exatamente por apresentar-se de forma contraditória, dialética e marcada pela bipolaridade possibilita espaços e práticas que conduzem à correlação de forças.

A gestão democrática se apresenta então como uma possibilidade de aprendizagem para o exercício democrático à medida que contribui com o rompimento de práticas autoritárias clientelistas e excludentes alavancando um processo de formação da classe trabalhadora a partir do trabalho desenvolvido no espaço público. Baquero (2008) defende a necessidade de compreender o papel que a história, a cultura política e o ser humano exercem nas representações políticas para buscar a democracia e, estas não podem ser deixadas de lado em função de regras, procedimentos ou mesmo instituições, tendo em vista que a participação precisa ser defendida.

Para regulamentar a participação as leis orgânicas específicas passaram a normatizar o direito constitucional, por meio de conselhos deliberativos, de composição paritária entre representantes do Poder Executivo e de instituições da 


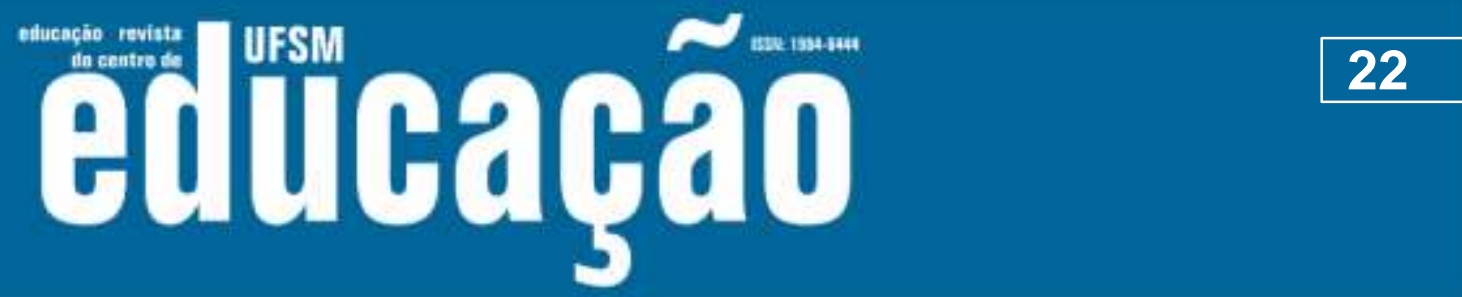

ISSN: 1984-6444 | http://dx.doi.org/10.5902/1984644430227

sociedade civil, dentre estas se fazem presentes os conselhos. A participação civil passa então a se efetivar com intervenções planejadas e periódicas, dando um novo enfoque para as políticas públicas e, no caso dos conselhos, deu-se a institucionalização entendida como inclusão no arcabouço jurídico institucional do Estado, a partir de estruturas de representação criadas por leis.

Nesta conjuntura, a pesquisa realizada em Fortaleza por meio da análise das Atas do CME de Fortaleza, bem como os dados obtidos com a UNCME, sinaliza para o fato de que apesar de ainda ser um instrumento imperfeito, considerando existir problemas institucionais para sua instalação e atuação, os conselhos se apresentam como instrumentos, que sendo aperfeiçoados, se tornam um embrião para a gestão colegiada, no qual se possibilita uma articulação com os interesses da comunidade escolar.

Maria da Glória Gohn (2001) assegura que historicamente os conselhos são antigos tanto quanto a democracia participativa e cita como exemplo países como Portugal no qual foram criados conselhos municipais como forma política administrativa. Gohn sublinha ainda que, o debate sobre os conselhos como instrumento de exercício da democracia é um tema da agenda de propostas para a gestão pública, que se coloca tanto entre os setores liberais como nos da esquerda. A autora salienta, entretanto, a diferença de como eles são pensados, pelos liberais, como "instrumentos ou mecanismos de colaboração, e, pela esquerda, como vias ou possibilidades de mudanças sociais no sentido de democratização das relações de poder". (GOHN, 2006, p.6).

O que se salienta a partir dos estudos que estão sendo realizados é que os conselhos precisam ter capacidade, poder de decisão e quando implantados, devem ser instâncias com autonomia e comprometimento com os interesses populares. Defende-se, portanto, que o espaço público que legitima a luta por democracia, ainda é, por essência, um campo profícuo para desenvolver-se uma contra-hegemonia, além do fato de que a história não é linear, ela é feita por homens, logo a transformação é possível e, é extremamente importante ir experimentando e apontando para a promessa de um tempo em construção: o tempo da gestão democrática. 


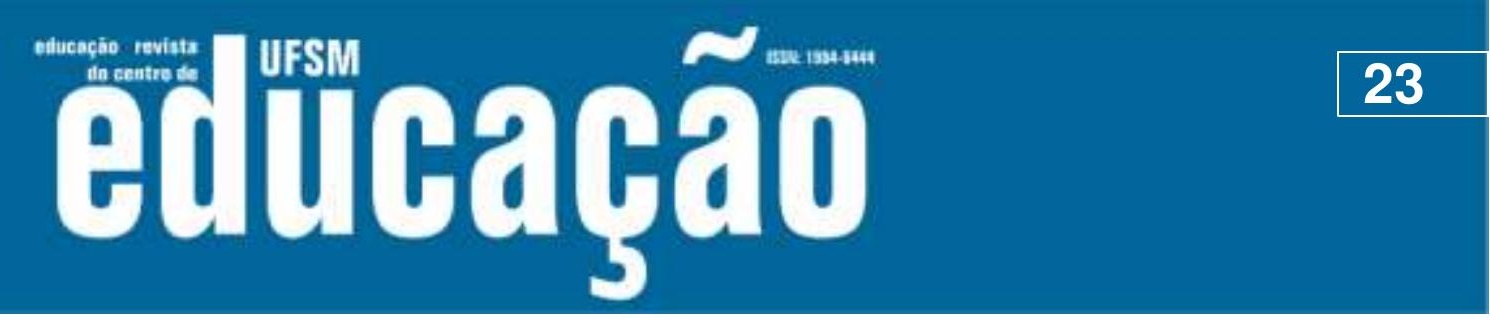

ISSN: 1984-6444 | http://dx.doi.org/10.5902/1984644430227

\section{Referências}

BAQUERO, Marcelo. Democracia formal, cultura política informal e capital social no Brasil. Revista Opinião Pública, Campinas, vol. 14, no 2, Novembro, 2008, p.38041.

BEHRING, Elaine Rossetti. Brasil em Contrarreforma: desestruturação do Estado e perda de direitos. São Paulo. Cortez, 2003.

BIANCHETTI, Roberto G. Modelo neoliberal e políticas educacionais. $2^{\underline{a}}$ ed. São Paulo: Cortez, 1999.

BORDENAVE, Juan E. Diaz. O que é participação. São Paulo: Brasiliense, 1994.

BORDIGNON, Genuíno. Gestão da Educação no Município: sistema, conselho e plano. vol. 3 - Editora e Livraria Instituto Paulo Freire - 1a. edição - 2009.

BRASIL, Constituição (1988). Constituição da República Federativa do Brasil. São Paulo: Saraiva, 2006.

BRASIL. Ministério da Educação e Cultura. Lei no 9.394 de 20 de dezembro de 1996. Diário Oficial da República Federativa do Brasil. Brasília, DF, v.135, n. 24,20 dez. 1996.

BRASIL. Bases da Educação Nacional, a 1a LDB - Lei no 4.024/1961. Disponível em: http://www.planalto.gov.br/ccivil_03/leis/L4024compilado.htm. Acesso em: 05/10/2017.

BRASIL. Ministério da Educação e Cultura. Lei $n^{\circ}$ 9.424. Disponível em: http://www.planalto.gov.br/ccivil_03/leis/L9424compilado.htm. Acesso em: 12/out.2017.

BRASIL. Presidência da República - Câmara da Reforma do Estado. Plano Diretor da Reforma do Aparelho do Estado. Brasília. 1995.

BRASIL. Controle Social. 2017. Disponível em: http://www.portaltransparencia.gov.br/ controleSocial. Acesso em 05/11/2017.

CONSELHO MUNICIPAL DE EDUCAÇÃO DE FORTALEZA/CE. Ata LXXX da Reunião Ordinária realizada no dia 10 de Dezembro de 2014.

CONSELHO MUNICIPAL DE EDUCAÇÃO DE FORTALEZA/CE. Ata LXXIV da Reunião Ordinária realizada no dia 07 de Dezembro de 2014.

CONSELHO MUNICIPAL DE EDUCAÇÃO DE FORTALEZA/CE. Ata LXXXII da Reunião Ordinária realizada no dia 04 de Fevereiro de 2015.

COUTINHO, Carlos Nelson. A democracia como valor universal. In: SILVEIRA, Enio et al. Encontros com a Civilização Brasileira. Rio de Janeiro: Civilização Brasileira, 1979, p.33-37. 


\section{Lusm

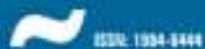

ISSN: 1984-6444 | http://dx.doi.org/10.5902/1984644430227

COUTINHO, Carlos Nelson. A democracia na batalha das ideias e nas lutas políticas do Brasil de hoje. In:

FÁVERO, O e SEMERARO, G. (orgs.). Democracia e a construção do público no pensamento educacional brasileiro. Petrópolis. Vozes. 2002. p. 11-40.

FÁVERO, O e SEMERARO, G. (orgs.). Gramsci: um estudo sobre seu pensamento político. Rio de Janeiro: Civilização Brasileira; 2012.

FRIGOTTO, Gaudêncio. A produtividade da escola improdutiva. São Paulo: Cortez Editora, 2006.

GOHN, Maria da Gloria M. Conselhos gestores e gestão pública. Revista de Ciências Sociais Unisinos 42(1):5-11, jan/abr 2006. Disponível em: file://C:/Users/Usuario/Downloads/6008-18468-1-SM\%20(1).pdf. $\quad$ Acesso em: 01/10/2017.

GOHN, Maria da Gloria M. Conselhos Gestores e participação sociopolítica. São Paulo. Cortez, 2001.

GOHN, Maria da Gloria M. O Papel dos Conselhos Gestores na Gestão Urbana In: Repensando a Experiência Urbana na América Latina: questões, conceitos e valores ed. Buenos Aires: CLACSO, 2000.

GRAMSCI, Antônio. Cadernos do Cárcere. Maquiavel - Notas sobre o Estado e a Política. vol. 3. Trad. Carlos Nelson Coutinho. Rio de janeiro: Civilização Brasileira, 2004.

GRAMSCI, Antônio. Cadernos do Cárcere. Maquiavel. Notas sobre o Estado e a política. V.3. Rio de Janeiro: Editora Civilização Brasileira, 2012.

GRAMSCI, Antônio. Escritos Políticos. Rio de Janeiro: Civilização Brasileira, 2004.

HOBSBAWN, Eric. A era dos extremos: o breve século XX. 1941-1991. São Paulo: Companhia das Letras, 1995.

KRAWCZYK, Nora Rut. O Plano Decenal de Educação Estadual: reflexões para pensar os desafios do Ensino Médio. NO PRELO, In: ALBUQUERQUE, Maria Gláucia Menezes Teixeira; FARIAS, Isabel Maria de Sabino; RAMOS, Jeanntte Filomeno Pouchain. (org.) Educação Básica Contemporânea: política, planejamento e gestão. Fortaleza. UECE. 2008. p.55-77.

LENIN, Vladimir llich. O Estado e a Revolução. Sao Paulo: Alfa-Omega, 1988.

LIBÂNEO, José Carlos. Organização e gestão da escola: teoria e prática. Goiânia. Editora Alternativa, 2001.

MARX, Karl. A ideologia alemã. 9o ed. São Paulo: Hucitec, 1993.

MARX, Karl. O 18 Brumário de Luiz Bonaparte. São Paulo: Centauro, 2003.

MICHELANGELO, Bovero (org.). Norberto Bobbio - Teoria Geral da Política. Editora Campus, 14ª Edição. 2000. pág 113. 


\section{Ailloapẫ}

ISSN: 1984-6444 | http://dx.doi.org/10.5902/1984644430227

PARO, Vitor Henrique. Gestão democrática da escola pública. 3. ed. São Paulo: Ática, 2008.

RAMOS, Jeannette Filomeno Pouchain. Projeto Educativo e Político-Pedagógico da Escola de Ensino Médio: tradições e contradições na gestão e na formação para o trabalho. Diss. http://www. teses. ufc. br, 2009.

ROSENFIELD, Denis L. O que é democracia. 5.ed. São Paulo: Ateniense, 1994.

SHIROMA, E.O; MORAES, M.C.M de; EVANGELISTA, O. Política Educacional. 2 ed. R.J. DP\&A. 2002.

SHIROMA, Eneida Oto; MORAES, Maria Célia de; EVANGELISTA, Olinda. Política Educacional. Rio de Janeiro. DP\&A. 2002.

UNIÃO NACIONAL DOS CONSELHOS MUNICIPAIS DE EDUCAÇÃO. Situação dos Municípios quanto a existência de Conselhos de Educação e Sistemas próprios de Ensino, criados legalmente. Disponível em: http://www.uncme.com.br/?pag=11\&men=379. Acesso em 08/09/2017.

ZIENTARSKI; SAGRILLO; PEREIRA. Os desafios dos professores na construção de uma escola pública democrática no contexto capitalista. Revista e-Curriculum. v.11. n. 01. abr/2013. ISSN: 1809-3876. p.114-135. São Paulo. 2013, Disponível em: https://revistas.pucsp.br/index.php/curriculum/article/view/8166/11309. Acesso em: 05/10/2017.

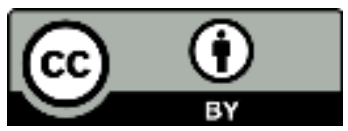

This work is licensed under a Creative Commons Attribution 4.0 International (CC BY 4.0). 